\title{
Anorectal Emergencies: Perianal Abscess
}

\author{
Aybala Yildiz ${ }^{1}$, Alp Yildiz ${ }^{1 *}$, Veysel Baris Turhan², Engin Kucukdiler ${ }^{3}$ \\ and Erkan Karacan ${ }^{3}$ \\ ${ }^{1}$ Department of General Surgery, Yenimahalle Training and Research Hospital, Yildirim \\ Beyazıt University, Ankara, Turkey \\ ${ }^{2}$ Department of General Surgery, Kecioren Training and Research Hospital, Ankara, \\ Turkey \\ ${ }^{3}$ Department of General Surgery, Aydin State Hospital, Aydin, Turkey \\ *Corresponding Author: Alp Yildiz, Department of General Surgery, Yenimahalle \\ Training and Research Hospital, Yildirim Beyazıt University, Ankara, Turkey.
}

Received: May 08, 2020

Published: June 23, 2020

(C) All rights are reserved by Alp Yildiz., et al.

\begin{abstract}
Anorectal emergencies refer to anorectal disorders presenting with some alarming symptoms such as acute anal pain and bleeding which might require an immediate management. Emergencies such as acutely thrombosed external hemorrhoid, thrombosed or strangulated internal hemorrhoid, bleeding hemorrhoid, bleeding anorectal varices, anal fissure, irreducible or strangulated rectal prolapse, anorectal abscess, perineal necrotizing fasciitis (Fournier gangrene), retained anorectal foreign bodies and obstructing rectal cancer. In this study we present our ambulatory management of perianal abscess. Fifty-two consecutive cases included this study. The patients admitted to outpatient clinic with anal pain, lump and/or purulent leak. All patients has diagnosed perianal abscess with physical examination. Patients has transferred the ambulatory surgery department for drainage. All abscesses drained at the bedside. Postoperative 1 patient admitted emergency service with anal pain which controlled NSAID injection. 1 patient presented with recurrent anal abscess on 8th postoperative day. No intra/postoperative bleeding/need for secondary powder application or postoperative anal incontinence detected. The main management of perianal abscess is surgical drainage. We present our series of perianal abscess treated with abscess drainage as day-care surgery with review of literature.
\end{abstract}

Keywords: Perianal Abscess; Anorectal Emergencies; Drainage

\section{Introduction}

Anorectal emergencies refer to anorectal disorders presenting with some alarming symptoms such as acute anal pain and bleeding which might require an immediate management [1]. Emergencies such as acutely thrombosed external hemorrhoid, thrombosed or strangulated internal hemorrhoid, bleeding hemorrhoid, bleeding anorectal varices, anal fissure, irreducible or strangulated rectal prolapse, anorectal abscess, perineal necrotizing fasciitis (Fournier gangrene), retained anorectal foreign bodies and obstructing rectal cancer [1]. In this study we present our ambulatory management of perianal abscess.

\section{Patients and Methods}

Fifty-two consecutive cases included this study. The patients admitted to outpatient clinic with anal pain, lump and/or purulent leak. All patients has diagnosed perianal abscess with physical examination. Patients has transferred the ambulatory surgery department for drainage. All abscesses drained at the bedside under local anesthesia. 2\% prilocaine hydrochloride used for local anesthesia. At prone-jackknife position the abscess has drained with no:11 surgical blade. The abscess cavity irrigated with saline solution and debridement performed. Hemostasis obtained with hemostatic powder (Arista ${ }^{\mathrm{TM}}$, Bard, USA/Oxicel Powder, Betatech Med, Istanbul, Turkey) packing inside the cavity. If hemorrhagia continues secondary application of powder then electrocauterisation planned. After procedure all patients has prescribed antibiotics and analgesic/anti-inflammatory drugs. After 4 hours of resting at ambulatory surgery clinic the patients discharged. All patients has evaluated in respect of perioperative complications from patients files retrospectively.

\section{Results}

All patients with perianal abscess also examined with rigid rectoscopy, in respect of anal fissure, perianal fistula, perianal hema- 
toma, pruritus ani, thrombosed piles, rectal ulcers for Crohn's disease, solitary rectal ulcer, fecal impaction, proctitis, rectal prolapse, anorectal malignancy. 2 patient diagnosed anal fissure, 3 patient hemorrhoidal disease and 1 patient solitary rectal ulcer. During drainage no intraoperative complication has occurred. Patients followed at least 10 days. Postoperative 1 patient admitted emergency service with anal pain which controlled NSAID injection. 1 patient presented with recurrent anal abscess on 8th postoperative day. No intra/postoperative bleeding/need for secondary powder application or postoperative anal incontinence detected.

\section{Discussion and Conclusion}

Anorectal abscesses are collections of pus within the dermis and deeper skin tissues, most often due to cryptoglandular infection or associated inflammatory bowel disease. Perianal abscesses are the most common type of anorectal abscess [2]. Patients with anorectal abscess may have discomfort and even severe pain. The incidence of anorectal abscess varies among countries and areas. It affects an estimated 18,000 patients in the UK every year [2] and the annual incidence is 16.1 per 100,000 in Sweden [2].

About $90 \%$ of idiopathic perianal abscesses occur because of infection of the cryptoglobular glands [3-5]. Most occur posteriorly and in the intersphincteric space, where the anal glands are located. Abscesses are classified as superficial or deep in relation to the anal sphincter. If the infection bursts through the external sphincter, it will form an ischiorectal abscess. If it spreads laterally on both sides it can form a collection of sepsis, which forms a 'horseshoe' around the sphincters [3-5]. Superior extension (supralevator abscess) beyond the puborectalis or the levators is rare and may represent iatrogenic injury (such as inadvertent injury from a fistula probe) [3-6] presentations of abscesses are perianal (up to 60\%) and ischiorectal [3]. Great percentage of these patients present with anal pain. Anal pain is among the most frequent complaints referred in coloproctology clinic $[7,8]$. The pain originated from the anal canal or the perianal region may also present great variability as far as the origin of the etiology of this symptom. Anal fissure, perianal fistula, anorectal abscesses as well as perianal hematoma are among the most frequent causes of pain at the perianal region [7-9]. Less common causes of anal pain may include pruritus ani, thrombosed piles, Crohn's disease, solitary rectal ulcer syndrome, fecal impaction, proctitis, rectal prolapse, anorectal malignancy, as well as chronic idiopathic syndromes, such as levator ani syndrome, coccygodynia, and proctalgia fugax [7-10].

The main management of perianal abscess is surgical drainage. We present our series of perianal abscess treated with abscess drainage as day-care surgery with review of literature.

\section{Bibliography}

1. Lohsiriwat V. "Anorectal emergencies". World Journal of Gastroenterology 22.26 (2016): 5867-5878.

2. Lu D., et al. "Relationship Between Body Mass Index and Recurrence/Anal Fistula Formation Following Initial Operation for Anorectal Abscess". Medical Science Monitor 25 (2019): 7942-7950.

3. Sahnan K., et al. "Perianal abscess". British Medical Journal 356 (2017): j475.

4. Eisenhammer S. "The internal anal sphincter and the anorectal abscess". Surgery, Gynecology and Obstetrics 103.4 (1956): 501-506.

5. Parks AG., et al. "A classification of fistula-in-ano". British Journal of Surgery 63.1 (1976): 1-12.

6. Whiteford MH. "Perianal abscess/fistula disease". Clinics in Colon and Rectal Surgery 20.2 (2007): 102-109.

7. Gkegkes ID and Stamatiadis AP. "Anal Pain of an Unusual Cause: Role of Endoanal Ultrasound". Journal of Medical Ultrasound 27.2 (2019): 107-109.

8. Givel JC. "Symptomatology of anorectal diseases". In: Marti MC, Givel JC, editors. Surgery of Anorectal Diseases with Pre- and Postoperative Management. $2^{\text {nd }}$ edition. Berlin: Springer-Verlag Berlin Heidelberg (1990): 13.

9. Townsend CM., et al. "Sabiston Textbook of Surgery". 19 th $^{\text {th }}$ edition. Philadelphia: Elsevier Saunders (2012).

10. Christiansen J. "Chronic idiopathic anal pain". European Journal of Surgery 164.2 (1998): 83-88.

\section{Assets from publication with us}

- Prompt Acknowledgement after receiving the article

- Thorough Double blinded peer review

- Rapid Publication

- Issue of Publication Certificate

- High visibility of your Published work

Website: https://www.actascientific.com/

Submit Article: https://www.actascientific.com/submission.php Email us: editor@actascientific.com

Contact us: +919182824667 